\title{
Sinonasal Anatomical Variation in Chronic Rhinosinusitis Patients Based on CT Scan Finding
}

\author{
Nikita Frinadya* \\ Faculty of Medicine, Universitas Sumatera \\ Utara, Medan, Indonesia \\ H. Adam Malik General Hospital, \\ Medan, Indonesia
}

\author{
Delfitri Munir \\ Faculty of Medicine, Universitas Sumatera \\ Utara, Medan, Indonesia \\ H. Adam Malik General Hospital, \\ Medan, Indonesia
}

\author{
Andrina Y. M. Rambe \\ Faculty of Medicine, Universitas Sumatera \\ Utara, Medan, Indonesia \\ H. Adam Malik General Hospital, \\ Medan, Indonesia
}

\begin{abstract}
Sinonasal disease, especially rhinosinusitis, is the most prevalent disease in the Otorhinolaryngology-Head and Neck Surgery Department. Different anatomical variations of the lateral walls of the nose play an important role in contributing to osteomeatal complex obstruction and drainage and ventilation distruption, which eventually causes inflammation of the sinus mucosa. To discover the characteristics of sinonasal anatomical variations in patients with chronic rhinosinusitis based on their CT scan findings. This is an observative descriptive study using a cross-sectional design. All chronic rhinosinusitis patients who came to Otorhinolaryngology in H Adam Malik General Hospital and Universitas Sumatera Utara Hospital, Medan, Indonesia, will undergo CT Scan examination to explore their anatomical variation. This study's inclusion criteria are a patient diagnosed with chronic rhinosinusitis, which is not diagnosed with a nasal polyp, who does not have a history of nasal trauma and has no history of previous nasal surgery. Of 40 patients with chronic rhinosinusitis, 21 patients were male, and 19 patients were female. The most prevalent anatomical variation found is a septal deviation (18 patients/ 45\%), with maxillary sinus as the most involved sinus (85\%). From the CT scan findings of chronic rhinosinusitis patients, the most prevalent anatomical variation is a septal deviation found in 18 patients (45\%). This high incidence of anatomical variation needs proper preoperative assessment for safe and effective endoscopic sinus surgery.
\end{abstract}

Keywords: Chronic rhinosinusitis, anatomical variation, CT scan.

Received: 10 May 2018; Accepted: 21 June 2018; Published: 13 July 2018

\section{INTRODUCTION}

Sinonasal disease, especially rhinosinusitis, is the most prevalent disease in the Otorhinolaryngology Head and Neck Surgery Department. Several anatomical variation such as septal deviation, agger nasi cell, and Haller's cell are among the most prevalent anatomical variations found. CT scan and nasal endoscopy are preffered diagnostic approaches to determine mucosal abnormalities or anatomical variations of paranasal sinuses that would potentially cause rhinosinusitis [1].

Chronic rhinosinusitis has high prevalency. According to National Health Interview Survey 1996 in the

\footnotetext{
${ }^{*}$ Correspondence concerning this article should be addressed to Nikita Frinadya, Faculty of Medicine, Universitas Sumatera Utara, Medan, Indonesia H. Adam Malik General Hospital, Medan, Indonesia. E-mail: frinadya@gmail.com

(c) 2018 The Author(s). Published by KKG Publications. This is an Open Access article distributed under a Creative Commons AttributionNonCommercial-NoDerivatives 4.0 International License.
} 
United States, chronic rhinosinusitis is estimated to be suffered by $12.5 \%$ of total population which corresponds to about 31 million patients yearly [2]. The prevalence of chronic rhinosinusitis in Indonesia varies. In 2000-2006, the number of cases of chronic rhinosinusitis in Dr. Sardjito Hospital, Jogjakarta was as much as $2.5-4.6 \%$ [3]. Chronic rhinosinusitis patients in H. Adam Malik General Hospital Medan in 2008-2009 was as much as 296 patients of 783 registered patients in Rhinology Division [4].

Several writers have assessed the correlation between sinonasal anatomical variation and rhinosinusitis insidence. Different anatomical variation found in the lateral walls of the nose play important role in causing obstruction of the osteomeatal complex and contributing to drainage and ventilation distruption, which eventually cause sinus mucosa inflammation [5].

Sinonasal anatomical variation as the etiology of sinusitis is mostly debatable. It is still widely accepted that the obstruction of the osteomeatal complex causes obstruction of the air flow, thus causing futher obstruction. From previous study, it is found that anatomical variation of the sinonasal can cause osteomeatal complex obstruction, which is the predisposising factor of rhinosinusitis. The most prevalent anatomical variations that may cause sinusitis is agger nasi cell (98\%), followed by septal deviation (70\%) consecutively [1].

CT scan assessment is the most common workup in oromaxillofacial cases. Anatomical variation of paranasal sinuses found through CT examination is important to decrease the risk during surgery and to find predisposing factor that may potentially cause pathological condition $[6,7]$.

The development of surgical therapy as chronic rhinosinusitis treatment, using endoscopy, require thorough knowledge of the anatomy of nose lateral walls, paranasal sinuses, other important surrounding structures, and other anatomical variations that may be assessed through CT scan [8].

\section{METHOD}

This is an observational study in descriptive form with a cross-sectional design, aiming to evaluate the anatomical variation characteristics of nose that may potentially cause obstruction on sinus ostium. The study was conducted in Haji Adam Malik General Hospital, Medan, and Universitas Sumatera Utara Hospital.

The population of this study are the chronic rhinosinusitis patients that came to Otorhinolaryngology (ENT)/Head and Neck Surgery policlinic in Haji Adam Malik General Hospital, Medan, and Universitas Sumat- era Utara Hospital. Chronic rhinosinusitis is an inflammation of nasal mucosa and paranasal sinuses mucosa that last more than 12 weeeks, diagnosed with 2 major symptoms or 1 major symptom with 2 minor symptoms from the list of symptoms according to Task Force. The major symptoms are mucopurulent nasal secretion, nasal obstruction, facial pain, post-nasal drip, and smelling disturbance. The minor symptoms are headache, halitosis, toothache, sensation of pain/ fullness in ear, cough, and fever.

This study samples are the chronic rhinosinusitis patients in Haji Adam Malik General Hospital, Medan, and Universitas Sumatera Utara Hospital who meet the inclusion and exclusion criteria starting from April 2018 until the number of required study participants was met. Through calculation, the number of sample needed was 40 samples.

The inclusion criteria of this study is the total patient diagnosed with rhinosinusitis and patients who are not diagnosed with nasal polyp, who do not have history of nasal trauma, and who do not have history of previous nasal surgery. The exclusion criteria of this study are patients who withdrawn themselves from the study.

The samples who met the criteria and agreed to take part in the study signed a written informed consent and subsequently went through an anamnesis. After that, a non-contrast coronal paranasal sinus CT scan was conducted. CT scan results were then evaluated and analyzed using SPSS (Statistical Package for the Social Science).

\section{RESULTS}

The characteristics of study subjects were age and sex.

TABLE 1

STUDY SUBJECT CHARACTERISTICS

\begin{tabular}{lll} 
Characteristics & $n=40$ & $\%$ \\
\hline Age & & \\
$<16$ years old & 5 & 12.5 \\
16 - 30 years old & 15 & 37.5 \\
$31-45$ years old & 7 & 17.5 \\
46 - 60 years old & 10 & 25.0 \\
$>60$ years old & 3 & 7.5 \\
Sex & & \\
Men & 21 & 52.5 \\
Women & 19 & 47.5 \\
\hline
\end{tabular}

This study was participated by 40 subjects who fulfilled the inclusion criteria. The majority of subjects were men, which comprises of 21 people $(52.5 \%)$. The most prevalent age group of 16 - 30 years old comprises of 15 people $(37.5 \%)$. 
TABLE 2

MAJOR AND MINOR SYMPTOMS DISTRIBUTION

\begin{tabular}{|c|c|c|c|c|c|c|}
\hline \multirow[t]{2}{*}{ Symptoms } & \multicolumn{2}{|c|}{$(+)$} & \multicolumn{2}{|c|}{$(-)$} & \multicolumn{2}{|c|}{ Total } \\
\hline & $n$ & $\%$ & $n$ & $\%$ & $n$ & $\%$ \\
\hline Major Symptoms Mucopurulent Rhinorrea & 21 & 52.5 & 19 & 47.5 & 40 & 100 \\
\hline Nasal Obstruction & 34 & 85 & 6 & 15 & 40 & 100 \\
\hline Facial Pain & 14 & 35 & 26 & 65 & 40 & 100 \\
\hline Post Nasal Drip & 27 & 67.5 & 13 & 32.5 & 40 & 100 \\
\hline Smelling Disturbance & 1 & 2.5 & 39 & 97.5 & 40 & 100 \\
\hline Minor Symptoms & & & & & & \\
\hline Headache & 34 & 85 & 6 & 15 & 40 & 100 \\
\hline Halitosis & 0 & 0 & 40 & 100 & 40 & 100 \\
\hline Toothache & 0 & 0 & 40 & 100 & 40 & 100 \\
\hline Sensation of fullness in ear & 1 & 2.5 & 39 & 97.5 & 40 & 100 \\
\hline Cough & 0 & 0 & 40 & 100 & 40 & 100 \\
\hline Fever & 0 & 0 & 40 & 100 & 40 & 100 \\
\hline
\end{tabular}

The most prevalent major symptom found in chronic rhinosinusitis patients are nasal obstruction found in as much as 34 people (85\%). The second most prevalent ma- jor symptom is post nasal drip, which was reported by 27 patients $(67.5 \%)$, followed by mucopurulent rhinorrhea in 21 patients $(52.2 \%)$.

TABLE 3

CHARACTERISTICS OF PARANASAL SINUS CT SCAN FINDINGS

Characteristics

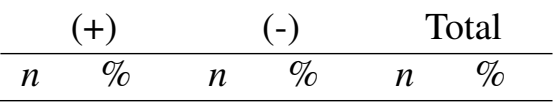

\begin{tabular}{lllllll} 
Anatomical Variation & & & & & & \\
Haller's Cell & 4 & 10 & 36 & 90 & 40 & 100 \\
Hipertrophic Ethmoidal Bulla & 0 & 0 & 40 & 100 & 40 & 100 \\
Uncinate Process Deviation & 16 & 40 & 24 & 60 & 40 & 100 \\
Paradoxical middle tubinate & 2 & 5 & 38 & 95 & 40 & 100 \\
Concha Bullosa & 9 & 22.5 & 31 & 77.5 & 40 & 100 \\
Septal Deviation & 18 & 45 & 22 & 55 & 40 & 100 \\
Onodi Cell & 2 & 5 & 38 & 95 & 40 & 100 \\
Frontal Cell & 0 & 0 & 40 & 100 & 40 & 100 \\
Agger Nasi Cell hypertropic & 2 & 5 & 38 & 95 & 40 & 100 \\
Paranasal Sinuses & & & & & & \\
Right Frontal & 3 & 7.5 & 37 & 92.5 & 40 & 100 \\
Left Frontal & 8 & 20 & 32 & 80 & 40 & 100 \\
Right Maxillary & 33 & 82.5 & 7 & 17.5 & 40 & 100 \\
Left Maxillary & 34 & 85 & 6 & 15 & 40 & 100 \\
Right Ethmoid & 20 & 50 & 20 & 50 & 40 & 100 \\
Left Ethmoid & 20 & 50 & 20 & 50 & 40 & 100 \\
Right Sphenoid & 6 & 15 & 34 & 85 & 40 & 100 \\
Left Sphenoid & 11 & 27.5 & 29 & 72.5 & 40 & 100 \\
\hline
\end{tabular}

Paranasal sinuses CT scan findings show septal deviation as the most prevalent anamotical variation in 18 patients (45\%). Uncinate process deviation falls onto second place with 16 patients $(40 \%)$, followed by concha 
bullosa with 9 patients $(22.5 \%)$.

Evaluation on paranasal sinuses shows left maxilla sinus to be the most prevalent, with 34 patients $(85 \%)$. The second most prevalent abnormality is found in right maxillary sinus, which is found in 33 patients $(82.5 \%)$. The third most prevalent abnormality is that of the right and left ethmoid, which was found in 20 patients (50\%).

\section{DISCUSSION}

This study shows that chronic rhinosinusitis is most prevalent in the 16-30 years old age group (37.5\%). In this study, the youngest patient is 8 years of age, where the oldest is 73 years of age. It is almost similar to the study conducted in Canada where it is most prevalently found in the 2029 years old age group and decreases after 60 years of age. According to European Position Paper on Rhinosinusitis and [9], chronic rhinosinusitis mostly affects young adults; its prevalence increases after puberty and gradually decreases in the middle age group and elderly [9].

Previous study cited by [10] showed that the increase of chronic rhinosinusitis cases in young adult is affected by various factors, such as environment, lifestyle changes, diet, and infection [10, 11, 12].

Its case is found more in men than women $(52.5 \%$ and $47.5 \%$ consequently). Similar report was made by [4], where the patients comprises of more men than women $[4,13]$.

Based on previous study by [5], 140 of 200 chronic rhinosinusitis patients at least have 1 anatomical variation found from their paranasal sinus CT scan finding, where men $(60.7 \%)$ were also more than women (39\%). Study conducted by [8] shows that of 60 patients diagnosed with chronic rhinosinusitis in the study, men were found as much as 36 pepople $(57 \%)$, where women were found as much as 24 people (43\%); the ratio of men:women is $1.5: 1$. The age range of the study subjects was $18-60$ years of age [5].

It is found that men may potentially suffers more from chronic rhinosinusitis than women, possibly because the different activities done by men and women, where men mostly spend their time outdoor, thus more prone to pollution, dust, cold air, and dry air that cause disruption of mucociliaary clearance [6].

This study also shows that the most common rhinosinusitis symptom is nasal obstruction ( $85 \%)$, followed by post nasal drip (67.5\%), and the rarest symptom is smelling disturbance $(2.5 \%)$. The most prevalent minor symptom encountered in this study is headache (85\%).

The result of this study is almost similar to that of [4, 14], in United States and [13], in Saudi Arabia, where the most prevalent symptom found was nose congestion. The study conducted by [15], in Makassar found that the most prevalent symptom in chronic rhinosinusitis patients was mucopurulent rhinorrhea $(83 \%)$, followed by nasal obstruction $(81.1 \%)$, and the rarest symptom was smelling disturbance (30.2\%). Study by [16], found post nasal drip to be the most prevalent symptom (95\%) followed by headache $(91 \%)$, runny nose $(90 \%)$, and nose congestion (86\%) consequently [4, 14, 17, 13, 15].

Based on paranasal sinus CT scan finding in this study, the most prevalent anatomical variation found is septal deviation (45\%), followed by uncinate process deviation/ hyperthrophy (40\%) and concha bullosa $(22.5 \%)$. This is consistent with the result showed by [5] study, where the most prevalent anatomical variation found was septal deviation $(58.5 \%)$, followed by bullous media conchae (49.3\%). Study done by [8], found $74.1 \%$ patients suffered from septal deviation. Similar result was found in Perez's study, which showed $80 \%$ patients suffered from septal deviation. In various other studies, septal deviation range between $14.1-80 \%$ [8].

In study done by [6], the most prevalent variation found was septal deviation (63\%). Septal deviation plays an important role in causing sinusitis and complications during endoscopic sinus surgery. The asymmetrical position of nasal septum pushes medial conchae more laterally, causing medial meatus to narrow, thus disrupting the drainage from maxillary sinus, anterior ethmoid sinus, and frontal sinus [6].

The correlation between septal deviation and chronic rhinosinusitis is due to the accumulation of secret in the sinus cavity caused by narrowing of the osteomeatal complex, which obstruct sinus cavity secretion and thus accumulating infection in the sinus cavity which will eventually causes chronic rhinosinusitis [18].

This study found that abnormality is mostly found in the left maxillary - found in 34 patients (85\%), followed by right maxillary $(82.5 \%)$, and right and left ethmoidal sinuses (50\%). Similar finding was also reported by [5], which shows that, based on the CT scan result of 106 sinusitis patients, sinusitis is mostly found in maxillary sinus $(67.1 \%)$, anterior ethmoid sinus $(54.3 \%)$, frontal sinus $(22.1 \%)$, posterior ethmoid sinus (10\%), and sphenoid sinus (10\%) [5].

Anatomical structure of maxillary made it susceptible to sinus drainage disruption, which is shown in $[19,15,16]$, study. Their study resonated the same result where maxillary sinus is the most prevalent site of sinusitis. The high incidence of sinusitis that is found in maxillary sinus and ethmoid sinus may happen because the drainage of maxillary sinus, ethmoid sinus, anterior 
and frontal sinus disembogues through medial meatus. So, when an anomaly happens in the osteomeatal complex, drainage and ventilation disruption on these three sinuses will happen and develop into sinusitis [18, 19, 16, 20].

\section{CONCLUSION}

It is concluded that anatomical variation found in chronic rhinosinusitis patients are those that interfere with osteomeatal complex. Septal deviation is the most prevalent, followed by uncinate process deviation/ hyperthrophy and concha bullosa.

CT scan examination needs to be done to assess the sinus and anatomical variation involved before sinus endoscopic surgery is performed.

\section{REFERENCES}

[1] K. Gouripur, U. Kumar, A. B. Janagond, S. Elangovan, and V. Srinivasa, "Incidence of sinonasal anatomical variations associated with chronic sinusitis by CT scan in Karaikal, South India," International Journal of Otorhinolaryngology and Head and Neck Surgery, vol. 3, no. 3, pp. 576-580, 2017. doi: https://doi.org/10.18203/issn.2454-5929. ijohns 20172291

[2] D. L. Hamilos, "Chronic rhinosinusitis: Epidemiology and medical management," Journal of Allergy and Clinical Immunology, vol. 128, no. 4, pp. 693-707, 2011. doi: https://doi.org/10.1016/j.jaci. 2011.08.004

[3] M. Harrowi, "The quality of life of patients with chronic rhinosinusitis post surgical therapy," Ph.D. dissertation, Universitas Gadjah Mada, Yogyakarta, Indonesia, 2007.

[4] Multazar, "Characteristics of chronic rhinosinusitis patients," Unpublished thesis, Universitas Sumatera Utaara, Medan, Indonesia, 2011.

[5] G. L. Fadda, S. Rosso, S. Aversa, A. Petrelli, C. Ondolo, and G. Succo, "Multiparametric statistical correlations between paranasal sinus anatomic variations and chronic rhinosinusitis," Acta Otorhinolaryngologica Italica, vol. 32, no. 4, p. 244251, 2012.

[6] A. Kamble, "Anatomical variations of the paranasal sinuses in chronic rhinosinusitis." IOSR Journal of Pharmacy and Biological Sciences, vol. 11, no. 4, pp. 20-23, 2016. doi: https://doi.org/10.9790/ 3008-1104032023

[7] J.-R. Park and J. E. Park, "A T-wave variation characteristics evaluation algorithm for ischemic heart beats," International Journal of Health and Med- ical Sciences, vol. 3, no. 3, pp. 80-84, 2017. doi: https://doi.org/10.20469/ijhms.3.30004-3

[8] A. Aramani, R. N. Karadi, and S. Kumar, "A study of anatomical variations of osteomeatal complex in chronic rhinosinusitis patients-CT findings," Journal of Clinical and Diagnostic Research, vol. 8, no. 10, p. KC01KC04, 2014. doi: https://doi.org/10. 7860/jcdr/2014/9323.4923

[9] W. J. Fokkens et al., "European position paper on rhinosinusitis and nasal polyps 2012. A summary for otorhinolaryngologists," Rhinology, vol. 50, no. 1, pp. 1-12, 2012. doi: https://doi.org/10.4193/ rhino50e2

[10] M. F. S., "Description of aerobic germs in maxillary sinus patterns in chronic maxillary rhinosinusitis patients performed surgical measures at $\mathrm{H}$. Adam Malik Hospital Medan," Unpublished thesis, Universitas Sumatera Utara, Medan, Indonesia, 2011.

[11] M. I. B. Bellini, "Brazilian health system: The interface between intersectoriality and interprofessional education," International Journal of Health and Medical Sciences, vol. 3, no. 2, pp. 54-58, 2017. doi: https://doi.org/10.20469/ijhms.3.30005-2

[12] M. Thilakarathna, "Issues encountered in community health in Sri Lanka with special reference to Polpithigama rural village in North-Western province," Journal of Advances in Health and Medical Sciences, vol. 3, no. 3, pp. 96-105, 2017. doi: https: //doi.org/10.20474/jahms3.3.1

[13] A. A. Aziz, H. S. Hassan, and K. A. Shama, "Functional endoscopic sinus surgery," Bahrain Medical Bulletin, vol. 28, no. 1, pp. 1-16, 2006.

[14] E. Dewi, M. Hasibuan, S. Nursiah, and Aliandri, "Profile of chronic rhinosinusitis patients undergoing actions of functional endoscopic sinus surgery in Medan H. Adam Malik Hospital 2008-2011," Unpublished thesis, Universitas Sumatera Utara, Medan, Indonesia, 2013.

[15] J. Bubun, A. Azis, A. Akil, and F. Perkasa, "Relation of symptoms and signs of chronic rhinosinusitis with CT scans based on Lund-Mackay scores," Master's thesis, Universitas Hasanuddin, Makassar, Indonesia, 2009.

[16] S. Nair, R. S. Bhadauria, and S. Sharma, "Impact of endoscopic sinus surgery on symptom manifestation of chronic rhinosinusitis," Medical Journal Armed Forces India, vol. 66, no. 1, pp. 41-45, 2010. doi: https://doi.org/10.1016/s0377-1237(10)80091-7

[17] D. Lal, J. M. Scianna, and J. A. Stankiewicz, "Efficacy of targeted medical therapy in chronic rhinosinusitis, and predictors of failure," American 
Journal of Rhinology \& Allergy, vol. 23, no. 4, pp. 396-400, 2009. doi: https://doi.org/10.2500/ajra. 2009.23 .3334

[18] O. A. Hasan, M. A. Hassan, E. K. Fawzy, and A. M. Maarouf, "Anatomical variation of nasal structures in chronic rhinosinusitis as detected by computed tomography scan," The Egyptian Journal of Hospital Medicine, vol. 68, no. 3, pp. 1390-1394, 2017. doi: https://doi.org/10.12816/0039679
[19] D. Munir, "Anatomical variation in chronic rhinosinusitis in H. Adam Malik Hospital, Medan," Majalah Kedokteran Nusantara, vol. 39, no. 3, pp. 225-229, 2006.

[20] P. H. Hwang and A. Abdalkhani, "Embryology, anatomy and physiology of the nose and paranasal sinuses," in Ballenger's Otorhinolaryngology: Head and Neck Surgery. Shelton, CT: People's Medical Publishing House, 2003. 